\title{
The centre edge angle of wiberg of acetabulum in adult jordanian population
}

\author{
Abstract \\ Objective: To measure the depth of acetabulum [the Centre edge (CE) angle] in adult \\ normal Jordanian population. \\ Design: Descriptive Case - Series Study. \\ Setting: King Abdullah University hospital, Jordan University of Science and Technology, \\ during the period May 2012 to May 2016.
}

Participants: Antero - posterior (AP) radiographs of (400 hips) taken for adult nonorthopedic patients of various age groups, 105 were men and 95 were women.

Main Outcome Measurements: The centre - edge (CE) angles of 400 hips were measured by Wiberg method.

Results: The (CE) angle increased with age. There is no significant difference between men and women, nor is a significant difference between right and left. The distribution of (CE) angles is similar to other studies in Indians, Caucasians and Africans.

Conclusion: The acetabular depth measured by the (CE) angle (acetabular dysplasia) could not be the main factor in etiology of osteoarthritis and congenital dislocation of the hip.

Key words: CE angle, hip, and normal Jordanian adult.
Volume 10 Issue 2 - 2018

\author{
Mwaffaq El-Heis,' Maha Gharaibeh,' \\ Mammon Al-Omari,' Ruba Khasawneh ${ }^{4}$ \\ 'Consultant radiologist \& associate professor, Radiology \\ department, Faculty of Medicine, Jordan University of science \\ and technology, Jordan \\ ${ }^{2}$ Radiology department, Faculty of Medicine Jordan University of \\ Science and Technology, Jordan
}

\begin{abstract}
Correspondence: Mwaffaq El-Heis, FRCR, FFRRCSI, CCST. Consultant radiologist \& associate professor, Radiology department, Faculty of Medicine, Jordan University of Science and Technology, Jordan, Tel +96279905 I50I, Email elhies@hotmail.com,
\end{abstract}

Received: March 16, 2018| Published: April 20, 2018

\section{Introduction}

The centre - edge (CE) angle of Wiberg is a measure of depth of acetabulum and of the cover of formal head. ${ }^{1,2}$ The (CE) angle increases very gradually though adult life. ${ }^{3}$ Large number of patients with primary osteoarthritis is in reality secondary to pre-existing asymptomatic anatomical abnormality, such as mild acetabular dysplasia. $^{4,5}$

In Caucasian congenital dislocation of the hip and primary osteoarthritis is common, while in Africans and Indians congenital dislocation of the hip and primary osteoarthritis are uncommon. ${ }^{1,6-8}$ In Arabic community, the congenital dislocation of the hip is common while primary osteoarthritis is uncommon. ${ }^{9,10}$ The aim of this study is to measure (CE) angle in Jordanian hips of various age groups. To compare the finding with published studies among adult Africans, Indians and Caucasian.

\section{Materials and methods}

The anteroposterior radiographs of both hips of 200 adult Jordanian of various age groups (400) hips are investigated. The study carried out at King Abdullah University Hospital in period May 2012 to May 2016. There were 105 men and 95 women aged between 20 and 75 years.

The radiographs had been performed mostly for Genito- urinary tract or gastro-intestinal conditions and in barium contrast studies and all the hips were reported to be normal. We measured the (CE) angle using the method described by Wiberg. ${ }^{11,3}$ The Centre of each femoral head is established by the superimposition of a circle round its margin. After these points have been joined, a line is draw from each of them to the edge of the articular surface of the corresponding acetabulum.
The angle formed between this line and vertical line from the centre of the femoral head is measured.

Although the (CE) angle can be measured with accuracy it was felt advisable to eliminate the possibility of observer error and all measurements were made by one of the authors (M.ELH). Comparison of the angles was made between the right and the left hips, and between men and women, and between age groups. The readings were also compared with the (CE) angles in other studies. The results were statistically analyzed by SPSS version 20 .

\section{Results}

In $80 \%$, the (CE) angle was between 24 and 41 degrees (Figure 1). None of the hips had (CE) angle of less than 18 degrees, which denote an acetabular dysplasia. In $1.5 \%$ it was between 18 and 23 which were described as uncertain by Wiberg. ${ }^{11}$ The maximum measured angle was 55 degrees. The average age were 39.5 years, $52.6 \%$ were between 20 and 40 years of age (Figure 2).

The average of (CE) angle in all hips was (38). There was no significant difference between men and women (Table 1) (Table 2). There was no significant difference between right and left hips (Table 1).

The (CE) angle of right and left hips were similar in $45 \%$ of patients, but the differences were less than 4 degrees in $45 \%$, the maximum difference was 10 degrees (Figure 3 ). There was significant difference in (CE) angle between the youngest subgroup and the other patients, between the oldest subgroup and the other patients, and between the youngest and the oldest subgroups (Table 3). The distribution of (CE) angle frequency shown in (Figure 2) was similar to other studies. As shown in Figure 4, normal center - edge angle and location was schemed. 


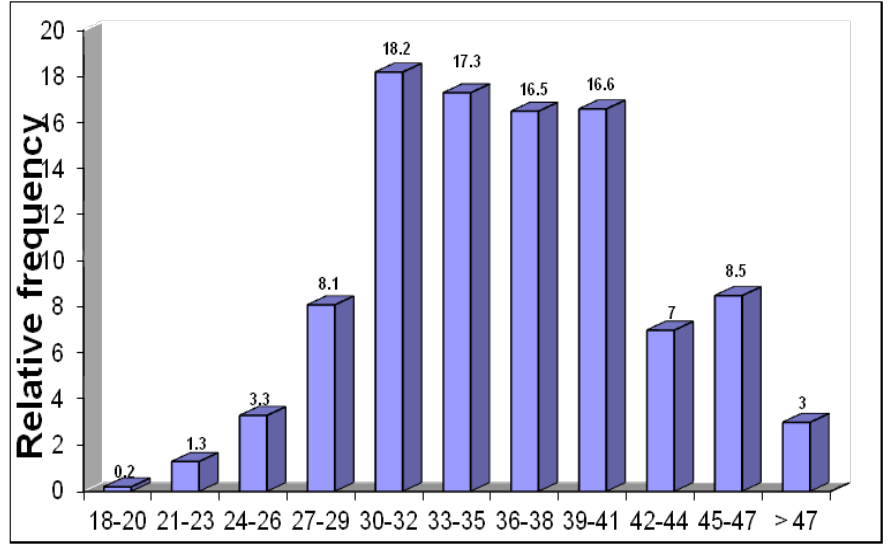

Figure I Distribution of Centre edge angle in study participants.

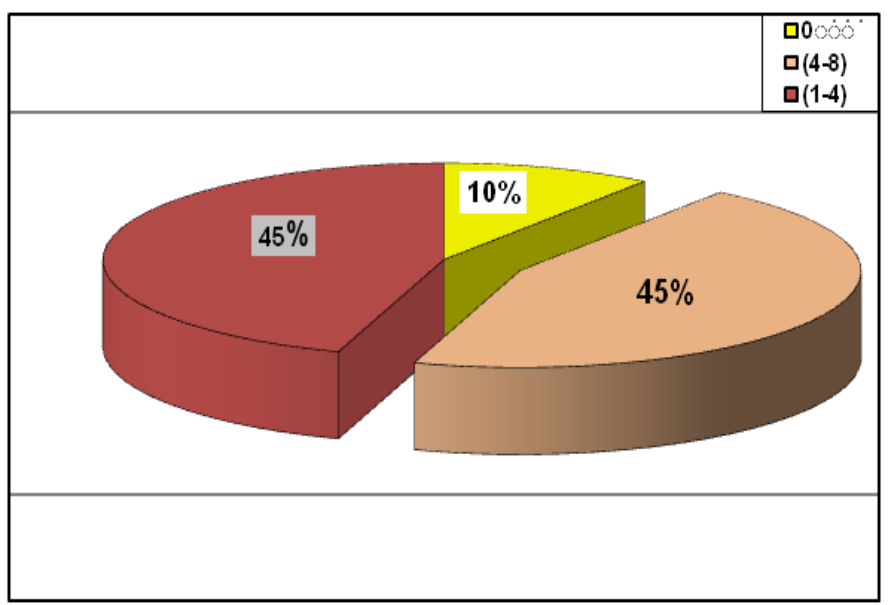

Figure 3 Distribution of the study subjects according to the difference (left and right) in centre edge angles (degree).

Table I Comparison in CE angle between the men and women, right and left

\begin{tabular}{llll} 
CE angle of & Mean & SD & P - value* \\
\hline men & 38 & 5.81 & \\
Women & 38 & 5.79 & N.S. \\
Left & 38 & 5.79 & \\
Right & 38 & 5.82 & N.S. \\
Women left & 38 & 5.55 & \\
Women Right & 38 & 5.80 & N.S. \\
Men Left & 38 & 5.97 & \\
Men Right & 37 & 5.78 & N.S.
\end{tabular}

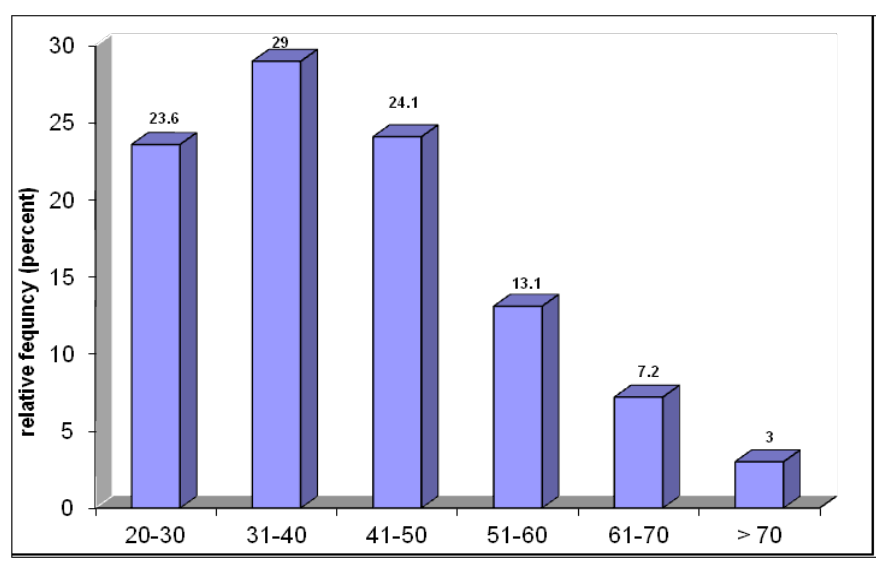

Figure 2 Distribution of age in study participants.

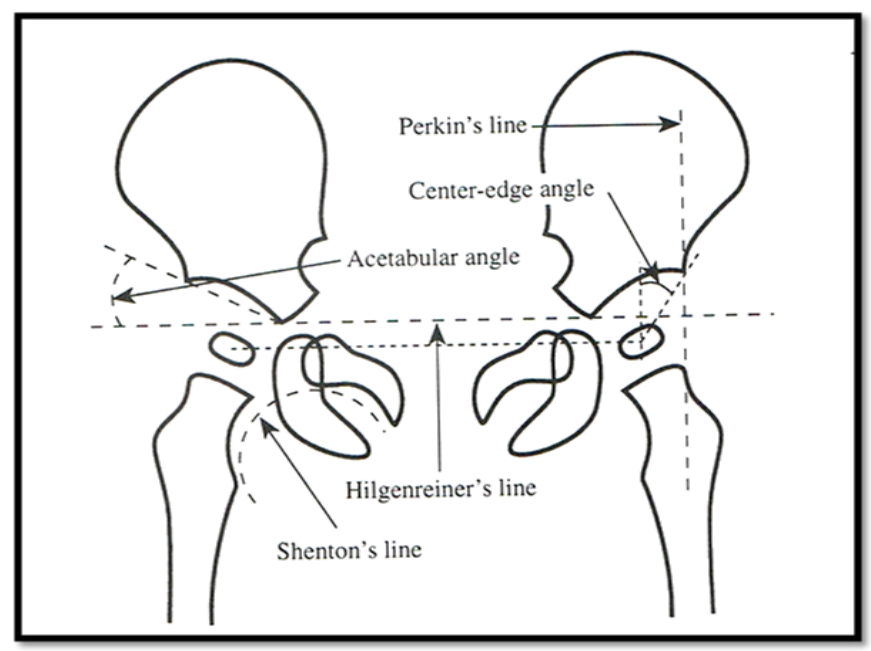

Figure 4 Shows normal center - edge angle and location.

Table 2 Measurement of CE angle (degrees) in 200 normal Jordanian subjects (400 hips)

\begin{tabular}{llll}
\hline $\begin{array}{l}\text { CE angle } \\
\text { (degrees) }\end{array}$ & \multicolumn{2}{c}{ Number of hips } & Total \% \\
\cline { 2 - 3 } & Men $(\mathbf{N}=\mathbf{2} 1 \mathbf{0}) \%$ & $\begin{array}{l}\text { Women } \\
(\mathbf{N}=190)\end{array}$ & \\
\hline $15-20$ & 0.6 & 1.6 & 2.2 \\
$20-25$ & 6.8 & 4.4 & 11.2 \\
$25-30$ & 12.1 & 18.4 & 30.5 \\
$30-35$ & 19.3 & 13.4 & 32.7 \\
$35-40$ & 8.4 & 6.2 & 14.6 \\
$40-45$ & 4.3 & 3.1 & 7.4 \\
$45-50$ & 0.6 & 0.8 & 1.4 \\
$50-55$ & 52.1 & 47.9 & $100 \%$ \\
\hline
\end{tabular}


Table 3 Comparison in CE angle between age groups

\begin{tabular}{llll}
\hline \multirow{2}{*}{ Age groups (years) } & \multicolumn{2}{c}{ CE angle (degrees) } & \multirow{2}{*}{ p- value* } \\
\cline { 2 - 3 } $20-30$ & Mean & SD & \\
Others & 35.35 & 5.57 & \\
$>50$ & 36.24 & 5.63 & $<0.01$ \\
Others & 37 & 5.33 & \\
$20-30$ & 36 & 5.29 & $<0.001$ \\
$>48$ & 35.40 & 5.57 & \\
\hline
\end{tabular}

$* \mathrm{Z}$ - test concerning two means (unpaired case) were used

\section{Discussion}

The human acetabulum is shallowest at the time of birth and becomes progressively deeper. ${ }^{12,13}$ Congenital dislocation of the hip is rare in some races including the Chinese, Bantu and Indian., ${ }^{3,14}$ In our Jordanian population the congenital dislocation of the hip is common.

The acetabular dysplasia may contribute to the incidence of congenital dislocation of the hip and it was consequently thought that there might be a variation in acetabular measurements between different population. ${ }^{12,13}$ It had been reported that there was no difference in depth of acetabulum as measured by the (CE) angle in adult African, Caucasian and Indian populations. ${ }^{1,3,14}$ Our study shows a similar pattern of distribution in adult Jordanian normal hips. These findings of similar distributions of acetabular depth in different population suggest that acetabular dysplasia may not have a significant role in the development of the condition.

Murray ${ }^{4}$ reported that at least $25 \%$ of cases of osteoarthritis in the hip were related to acetabular dysplasia and one expect, in view of rarity of osteoarthritis in the African, Indian and Arab, that acetabular dysplasia would be less frequent. . $^{1,3,10,14}$ The findings in this study and other studies of a similar distribution of acetabular depth suggests that acetabular dysplasia could only be a contributory factor in the etiology of osteoarthritis. ${ }^{1,3}$

In our study, we found that (CE) angle and acetabular depth increased significantly with age and becomes progressively deeper. Other studies reported the same results. This finding could be establish by the fact that the cartilage of the acetabulum and femoral head thins or softens and allows the head to sink just a little more deeply into acetabulum. ${ }^{1,3,12}$ The difference in $\mathrm{CE}$ angle between left and right hips is difficult to explain, but the differences in the loading stresses sustained by the two hips may account for the variations in acetabular depth. ${ }^{1}$

We conclude that $\mathrm{CE}$ angle distribution in our population is similar to other populations, and the acetabular dysplasia had only contributory factor in development of congenital dislocation of the hip and osteoarthritis of the hip. ${ }^{15-18}$

\section{Acknowledgements}

None.

\section{Conflict of interest}

There is no conflict of interest in publishing the article.

\section{References}

1. Mandal S, Bhan S. The Centre-edge angle of Wiberg in the adult Indian population. J Bone joint surg. 1996;78(2):320-321

2. Harris-Hayes M, Royer NK. The Relationship of Acetabular Dysplasia and Femoroacetabular Impingement to Hip Osteoarthritis: A Focused Review. PMR. 2011;3(11):1055-1067.

3. Skirving AP. The Centre-edge angle of Wiberg in adult Africans and Caucasians. J Bone Joint Surge. 1981;63B(4):567-578.

4. Murray RO. The etiology of primary osteoarthritis of the hip. Brit $J$ Radiol.1965;38:810-824.

5. Siverling S, O'Sullivan E, Garofalo M, et al. Hip osteoarthritis and the active patient: will I run again? Curr Rev Musculoskelet Med. 2012;5(1):24-31.

6. Lane NE, Lin P, Christiansen L, et al. Association of mild acetabular dysplasia with an increased risk of incident hip osteoarthritis in elderly white women: the study of osteoporotic fractures. Arthritis Rheum. 2000;43(2):400-4.

7. Lynch JA, Parimi N, Chaganti RK, et al. The association ofproximal femoral shape and incident radiographic hip OA in elderly women. Osteoarthritis Cartilage. 2009;17(10):1313-8.

8. Nelson E, Braga L, Benner J, et al. Characterization of individual radiographic features of hip osteoarthritis in African American and White women and men: the Johnston County Osteoarthritis Project. Arthritis Care Res. 2010;62(2):190-197.

9. Mir NA, Galczak WC, Soni AM. Easily identifiable congenital malformations in children. Ann Saudi Med. 1992;12(4):366-371.

10. Nagi ON, Dhillon MS. Complications after total hip arthroplasty- 10 years' experience in a developing country. Saudi Medical Journal. 1992;13(5):442-447.

11. Wiberg G. Shelf operations in congenital dysplasia of the acetabulum and in subluxation and dislocation of the hip. $J$ Bone Joint Surg. 1953;35A(1):65-80.

12. Ralis Z, McKibbin B. Changes in shape of the human hip joint during its development and their relation to its stability. J Bone Joint Surg. 1973;55(4):780-785

13. Giorgi M, Carriero A, Shefelbine S, et al. Effects of normal and abnormal loading conditions on morphogenesis of the prenatal hip joint: application to hip dysplasia. J Biomechanics. 2015;48(12):3390-3397.

14. Hofmann UK, Ipach I, Rondak IC, et al. Influence of age on parameters for femoroacetabular impingement and hip dysplasia in X-RAYS. Acta Ortop Bras. 2017;5(5):197-201.

15. Ahlberg A, Moussa M. Osteoarthritis of the knee in a Saudi Arabian population. Saudi Medical Journal. 1989;10(5):400-403.

16. AI-Mashhadani AR, Al-Barazanjy JS. Epidemiological study of congenital malformations in Baghdad. Master Thesis, College of medicine, University of Al-Mustansiriah, 1989.

17. Wynne-Davies R. Acetabular dysplasia and familial joint laxity: two etiological factors in congenital dislocation of the hip. $J$ Bone Joint surge. 1970;52(4):704-716.

18. Zhang Y, Jordan JM. Epidemiology of Osteoarthritis. Clin Geriatr Med. 2010;26(3):355-369. 